\title{
Kidney transplantation and other methods of renal replacement therapy in children: 30 years of observations in one center
}

\author{
Anna Medyńska ${ }^{A-F}$, Katarzyna Kiliś-Pstrusińska ${ }^{A-F}$, Irena Makulska ${ }^{C, F}$, Danuta Zwolińska ${ }^{E, F}$ \\ Department of Pediatric Nephrology, Wroclaw Medical University, Poland \\ A - research concept and design; $\mathrm{B}$ - collection and/or assembly of data; $\mathrm{C}$ - data analysis and interpretation; \\ $D$ - writing the article; $E$ - critical revision of the article; $F$ - final approval of the article
}

Address for correspondence

Katarzyna Kiliś-Pstrusińska

E-mail: katarzyna.kilis-pstrusinska@umed.wroc.pl

\section{Funding sources}

None declared

Conflict of interest

None declared

Received on March 20, 2020

Reviewed on April 14, 2020

Accepted on May 1,2020

Published online on May 28, 2020

\begin{abstract}
Background. Kidney transplantation (Tx) is regarded as the optimal treatment method for renal replacement therapy (RRT) for end-stage renal disease (ESRD) patients. Children qualified for Tx should receive the organ as soon as possible in order to improve their chances for healthy development. In our center, RRT for children with ESRD has been conducted for 36 years: hemodialysis (HD) since 1982, peritoneal dialysis (PD) since 1992 and the first transplant in 1987.
\end{abstract}

Objectives. To analyze the rates of different RRT methods in children with ESRD. Special attention was paid to Tx.

Material and methods. We compared the rates of RRT methods over 3 subsequent decades (1987-1996, 1997-2006 and 2007-2017).

Results. In the period analyzed, 153 children aged from 2 weeks to 18 years were dialyzed. The mean age of the start of RRT was 9.4 years. In 80 children (52.2\%), first method was HD, while in 73 patients (47.7\%) it was PD. In 25 children, the type of dialysis was changed. Kidney transplantation was performed in 40\%, $60.34 \%$ and $73 \%$ of patients dialyzed in the periods 1987-1996, 1997-2006 and 2007-2017, respectively. The average waiting time for a transplant in the abovementioned decades was 2.25 years, 2.65 years and 1.97 years, respectively. Three children underwent transplantation with a family donor; 1 boy received a transplanted kidney and liver. Two children underwent a preemptive transplant from a deceased donor.

Conclusions. The percentage of children with ESRD treated with Tx continues to increase, but in our assessment, it still remains too low. Among the types of dialysis, PD was much more frequently used, which is consistent with pediatric recommendations. Small number of transplants from a living donor and preemptive transplants indicates the need to promote organ donation in Polish society.

Key words: renal replacement therapy, kidney transplantation, children

Cite as

Medyńska A, Kiliś-Pstrusińska K, Makulska I, Zwolińska D. Kidney transplantation and other methods of renal replacement therapy in children: 30 years of observations in one center. Adv Clin Exp Med. 2020;29(5):611-613.

doi:10.17219/acem/121928

DOI

10.17219/acem/121928

Copyright

Copyright by Author(s)

This is an article distributed under the terms of the

Creative Commons Attribution 3.0 Unported (CC BY 3.0)

(https://creativecommons.org/licenses/by/3.0/) 


\section{Introduction}

Kidney transplantation ( $\mathrm{Tx}$ ) is undoubtedly the best method for renal replacement therapy (RRT) in children with end-stage renal disease (ESRD). ${ }^{1}$ In addition to the benefits that are universal for all kidney recipients, organ transplantation in children allows for the best physical development possible when it comes to chronic illness, as well as for noticeable benefits in the child's intellectual and social development. In the last 2 decades, the survival of patients who have been kidney recipients has improved significantly, as new groups of children are eligible for treatment with this method (e.g., patients who lost a transplant or who have been recipients of another transplant). The first pediatric patients were included in the RRT in the 1960s. ${ }^{2}$ In our clinic, hemodialysis (HD) has been available since 1982 and peritoneal dialysis (PD) since 1992. The first patient from our clinic received a transplant 30 years ago. Since then, the number of transplants in children treated for ESRD has been rising steadily, but many of them stay on the waiting list for a long time.

\section{Objectives}

The aim of the study was to assess the rates of Tx treatment in children with ESRD in comparison with other methods of chronic RRT. We analyzed the data of patients treated between 1987 and 2017; in particular, we compared the transplants conducted over 3 subsequent decades.

\section{Patients and methods}

We analyzed the data of patients treated with RRT in the period of 1987-2017.

The following factors were taken into account: the children's age, the children's age when dialysis began, the type of dialysis (HD or PD) used as the first method of RRT, possible alterations in the type of dialysis therapy, and the cause of ESRD. In the group of patients treated with Tx, we analyzed the following factors: the age at which the kidney was transplanted, the waiting time for Tx and the type of transplantation (transplantation from a deceased donor, from a living donor, or preemptive transplant).

The collective data analysis compared RRT over 3 decades: 1987-1996, 1997-2006 and 2007-2017. In the group of dialyzed patients, in the $2^{\text {nd }}$ or $3^{\text {rd }}$ decade, those who started dialysis in the given period and those who continued it from the previous decade were distinguished. In particular decades, the number of transplants was referred to the total number of patients dialyzed during the specified period. Among the transplanted patients, the group of children was separated from the group of adults. The latter included patients who, after reaching the age of 18 , were further dialyzed at the pediatric station and were transplanted under their care. The percentage of transplants in a given period was determined by referring the number of Tx to the number of dialyzed patients, regardless of the date of their inclusion in the dialysis program.

\section{Results}

In the period studied, 153 children aged from 2 weeks to 18 years (mean age: $10.17 \pm 5.63$ years) were dialyzed; the average age of the start of RRT was 9.4 years. The causes of ESRD were as follows: $49 \%$ - congenital anomalies of the kidney and the urinary tract, $40 \%$ - glomerulonephritis and $11 \%$ - other causes. In 80 children (52.2\%), the method utilized first was HD, while in 73 children (47.7\%) it was PD. In 25 children, the type of dialysis was changed.

In the period of 1987-1996, 41 children were hemodialyzed and 9 children were treated with PD. In the next decade, 26 children underwent RRT with HD, while 32 children were treated with PD. In 2007-2017, 13 children were treated with HD and 32 children were treated with PD. In the $1^{\text {st }}$ decade, Tx was performed in 14 children (including 13 on HD and 1 on PD) and in 6 young adults. In the next decade, Tx was carried out in 12 children treated with HD and in 17 who were treated with PD and started dialysis in this period. In addition, 6 patients who had undergone dialysis in the previous decade received a transplant (3 children and 3 young adults). Between 2007 and April 2017, hemodialysis was initiated in 13 children, whereas PD treatment was started in 32 patients. During this period, Tx was performed in 6 children treated with HD and in 17 children treated with PD. Similarly to the previous decade, transplants were also conducted in 8 children and 2 young adults who had started dialysis therapy earlier.

In total, Tx was performed in 20 (40\%), 35 (60.34\%) and 33 (73\%) of patients who were dialyzed in 1987-1996, 1997-2006 and 2007-2017, respectively. The average waiting time for a transplant in the abovementioned decades was 2.25 years, 2.65 years and 1.97 years, respectively (range: 6 months -10 years).

Among our patients, a transplantation from a family member in the analyzed period was performed only in 3 children who were dialyzed in the period of 1997-2006, which constitutes $1.96 \%$ of all patients on RRT in the entire period analyzed. One patient underwent a kidney and liver transplant. In the years 2007-2017, a preemptive transplant from a deceased donor (1.3\%) was performed in 2 children.

\section{Discussion}

End-stage renal failure in children is much less common than in adults, with an incidence rate of 5-10 per million each year. ${ }^{3}$ The causes of ESRD in the pediatric 
population are primarily congenital anomalies of the kidney and the urinary tract (CAKUT), followed by glomerulonephritis and other diseases. ${ }^{4}$ Among our pediatric patients, structural abnormalities of the urinary system were also the most common causes: we found them to be the cause in $49 \%$ of children.

The ten-year survival rate is about $80 \%$ in children with ESRD. However, the risk of death for dialyzed children remains 30 times higher than in the general population. ${ }^{5}$ Of all the methods of RRT, Tx is unquestionably the best method for ensuring proper physical and social development and for significantly improving quality of life. ${ }^{1}$

In Poland, about 100 children are waiting for $\mathrm{Tx}$, and the number of transplants is 35-45 per year. In 2015, 91 children were waiting for Tx and 35 transplants were carried out -28 from deceased donors and the rest from living donors. ${ }^{6}$ The average waiting time for a transplant is about 2 years, which is confirmed by our observations. In Poland, since January 1, 2016, the organ allocation system has been changed: currently, a donor up to the age of 18 is considered a donor for a child, a policy which may shorten the waiting time for organs among children.

The use of modern immunosuppression has improved the long-term prognosis for maintaining renal function after transplantation; it is $90-92 \%$ after 1 year and $75-80 \%$ after 5 years. $^{7}$

A preemptive Tx helps to prevent complications and the burden of dialysis. It also ensures better patient survival than any type of dialysis. ${ }^{5,8}$ Unfortunately, about $80 \%$ of children require an initial period of dialysis in preparation of Tx, or after its loss. ${ }^{9}$

In a study conducted by Amaral et al. on a very large group of children $(7,527)$ who received transplants in the USA from 2000 to 2012, it was shown that preemptive transplants from both living and deceased donors ensure longer graph survival and reduce the mortality of patients. ${ }^{8}$ In our group of children, a preemptive transplant from a deceased donor was performed in only 2 children (i.e., $1.3 \%)$. In research by Amaral et al., the vast majority of patients receiving a transplant before the start of dialysis received kidneys from living donors (66\% of all preemptive transplants), which was not confirmed in our small group of children.

Transplantation from a living donor not only provides for preemptive transplantation, but it also has a number of other benefits. Such a graft has a longer survival rate than grafts from a deceased donor. ${ }^{1}$ The biological quality of the kidney is better, which is associated with a shorter time of cold ischemia, ${ }^{1}$ and there is no brain-death-related damage to the graft, which occurs in deceased donors. ${ }^{10}$ Also, immunological matching remains at a more compatible level.

In our group of patients, a living donor transplant (from a family member) was performed in 3 children (during the $2^{\text {nd }}$ decade of observation), which is a small percentage (1.96\%) of all transplanted patients. In a study conducted by Perez-Bertolez et al., the rate of living donor transplants reached $38.27 \% .^{11}$

According to the North American Pediatric Renal Trials and Collaborative Studies, living donor transplants accounted for $61 \%$ of the total transplants in 2001 and dropped to $37 \%$ in $2007 .{ }^{12}$

\section{Summary}

Kidney transplantation continues to be the best option available for RRT in children. In subsequent decades, the number of transplants among our patients has increased. However, it should be emphasized that the number of children who start dialysis therapy has also increased. In the authors' opinion, it is important to promote organ donation, family donation in particular, among patients and their families.

\section{ORCID iDs}

Anna Medyńska (D) https://orcid.org/0000-0001-8191-045X Katarzyna Kiliś-Pstrusińska (D) https://orcid.org/0000-0001-7352-6992 Irena Makulska (D) https://orcid.org/0000-0001-8324-274X

Danuta Zwolińska (D) https://orcid.org/0000-0002-6714-3992

\section{References}

1. Roach JP, Bock M, Goebel J. Pediatric kidney transplantation. Semin Pediatr Surg. 2017;26:233-240.

2. Chesnaye NC, van Stralen KJ, Bonthuis M, Harambat J, Groothoff JW, Jager KJ. Survival in children requiring chronic renal replacement therapy. Pediatr Nephrol. 2018;33:585-594.

3. Van Arendonk KJ, Boyarsky BJ, Orandi BJ, et al. National trends over 25 years in pediatric kidney transplant outcomes. Pediatrics. 2014; 133(4):594-601.

4. Harambat J, van Stralen KJ, Kim JJ, Tizard EJ. Epidemiology of chronic kidney disease in children. Pediatr Nephrol. 2012;27(3):363-373.

5. McDonald SP, Craig JC. Long-term survival of children with end-stage renal disease. NEngl J Med. 2004;350(26):2654-2662.

6. [Poltransplant. Biuletyn Informacyjny, nr 1 (23), 2015. ISSN 1428-0825]. http://www.poltransplant.pl/Download/biuletyn2015_www.pdf. Accessed on December 15, 2019.

7. Grenda R, Kaliciński P. Organ transplantation in children. Kidney transplantation. An overview. In: Cierpka L, Durlik M, eds. Clinical Transplantation. Poznań, Poland: Termedia; 2015:223-233.

8. Amaral S, Sayed BA, Kutner N, Patzer RE. Preemptive kidney transplantation is associated with survival benefits among pediatric patients with end stage renal disease. Kidney Int. 2016;90(5):1100-1108.

9. Chesnaye N, Bonthuis M, Schaefer F, et al. Demographics of paediatric renal replacement therapy in Europe: A report of the ESPN/ERAEDTA registry. Pediatr Nephrol. 2014;29(12):2403-2410.

10. Jochmans I, Watson CJ. Taking the heat out of organ donation. NEngl J Med. 2015;373(5):477-478.

11. Perez-Bertolez S, Barrero R, Fijo J, at al. Outcomes of pediatric living donor kidney transplantation: A single-center experience. Pediatr Transplant. 2017;21(3):1-6.

12. Smith JM, Martz K, Blydt-Hansen TD. Pediatric kidney transplant practice patterns and outcome benchmarks, 1987-2010: A report of the North American Pediatric Renal Trials and Collaborative Studies. Pediatr Transplant. 2013;17(2):149-157. 